\title{
DIREITO E HUMANIDADES: ASPECTOS DA FORMAÇÃO HUMANA
}

\section{Aldemir Berwig ${ }^{1}$}

\section{Resumo}

Este artigo é uma reflexão sobre a formação humana nos cursos de Direito e observa que o ensino jurídico, mais que uma formação na área das ciências sociais aplicadas, deve ter a preocupação principal com a formação humana para a vida em sociedade. Trata-se de pesquisa qualitativa com reflexão a partir de estudo teórico. Conclui-se que há equívoco na forma como se ensina o Direito e se avalia a aprendizagem, o qual enfatiza a transmissão e memorização de conteúdos jurídicos. Ressalta-se que é necessário resgatar a unidade do saber humano emancipatório, que o conhecimento da dimensão humanística é que dá sentido ao ensino do Direito em uma universidade, com construção da autonomia de pensamento e não como uma simples formação para o mercado.

Palavras-chave: Autonomia; Ensino jurídico; Educação; Imaginário social; Relações humanas.

\section{Introdução}

Desde a última década do século passado tem ocorrido uma grande mudança na oferta de vagas em cursos superiores no Brasil ${ }^{2} \mathrm{e}$, de certa forma, a mercantilização da educação como decorrência da abertura para que empresas educacionais ${ }^{3}$ passem a atuar no país com a finalidade de lucro. Como consequência ocorrem mudanças nos sistemas de controle de qualidade para o funcionamento das entidades educacionais. $\mathrm{O}$ Estado e as corporações profissionais ${ }^{4}$, em alguns

\footnotetext{
${ }^{1}$ Doutor e Mestre em Educação nas Ciências (UNIJUÍ); Especialista em Direito Tributário (UNISUL); Graduado em Direito e Administração (UNIJUÍ); Professor do Departamento de Ciências Jurídicas e Sociais da UNIJUÍ; Coordenador do Comitê de Ética em Pesquisa (CEP) da UNIJUÍ; berwig@unijui.edu.br.

${ }^{2}$ A partir da década de 1990 ocorre a reestruturação do Estado sob o argumento de que ele deve ser menos interventor e passar a regular as atividades prestadas por entidades, em regra, não-estatais. Disso decorre a diversificação institucional da educação superior que, segundo dados do Censo do Ensino Superior de 2017 (BRASIL, 2018a), resultou num total de 2.448 Instituições de Ensino Superior (IES) no Brasil, sendo apenas 199 Universidades, 106 públicas e 93 privadas. Além destas, são 189 Centros Universitários (8 públicos e 181 privados), 2.020 Faculdades (142 públicas e 1.878 privadas), e 40 Institutos Federais e Cefets. Quando se fala em mercantilização do ensino ocorre a referência às entidades com fins lucrativos e à precarização das condições de ensino.

${ }^{3}$ Como decorrência da abertura da exploração da educação por entidades com finalidade lucrativa, o Estado passa a exigir qualidade na oferta, mas utiliza-se do discurso empresarial. Flávia Feitosa Santana (2007) menciona que o discurso da qualidade na educação superior é decorrente da gestão de empresas, tendo um cunho concorrencial e mercantilista. Este discurso de qualidade apresenta ambiguidades conceituais que dificultam o estabelecimento de qualquer padrão qualitativo, de forma que se pode falar de imaturidade conceitual, já que o ensino superior pode ser avaliado por diferentes ângulos, pela ótica do mercado, ou pela ótica da formação do cidadão e do profissional.

${ }^{4}$ É o caso da competência atribuída para o Conselho Federal da Ordem dos Advogados do Brasil pelo inciso XV do art. 54 da Lei n $^{\circ}$ 8.906/1994 (BRASIL, 1994) para colaborar com o aperfeiçoamento dos cursos jurídicos, e opinar, previamente, nos pedidos apresentados aos órgãos competentes para criação, reconhecimento ou credenciamento dos cursos jurídicos, mas desempenhado como um verdadeiro controle sobre as entidades através do desempenho de outra competência prevista para o Conselho Seccional no inciso VI do art. 58: realizar o Exame de Ordem. O Exame de Ordem, cuja finalidade seria a de selecionar os futuros quadros da entidade, termina sendo utilizado como mais uma avaliação dos cursos jurídicos, aspecto que contraria a previsão constitucional de
} 
casos, passam a exercer verdadeiro controle de qualidade sobre os cursos ofertados, os quais não proporcionam uma formação que conduza o indivíduo à autonomia esperada para a vida em uma sociedade complexa como a deste século. É neste contexto que se faz a análise da formação humana nos cursos jurídicos.

A análise conduz a questionamentos sobre os fundamentos do próprio ensino jurídico, o qual se pauta mais na observância do conteúdo do que de sua finalidade. Na graduação, fruto dessa cobrança equivocada, há uma preocupação maior com a memorização ${ }^{5}$ e com a aplicação dos instrumentos jurídicos e não com a finalidade a ser atingida com a utilização de tais mecanismos. A formação humana está voltada demasiadamente à técnica deixando de lado o aspecto humano, tão necessário à concretização do bem-estar coletivo.

Esta reflexão tem a pretensão de analisar o ensino jurídico e demonstrar a necessidade de uma preocupação que se volte ao humano. Observa-se que a educação é um direito constitucionalmente garantido a todos os indivíduos, mas esta garantia não é totalmente concretizada, já que existe uma verdadeira confusão ou incompreensão sobre o que se pode esperar de uma formação jurídica na atualidade. Assim, pode-se sugerir que existe a necessidade de formação superior que não é totalmente satisfeita no âmbito do ensino jurídico, para não dizer de toda a formação superior, o qual poderia modificar o modo de pensar das futuras gerações.

autonomia universitária didático-científica. Essa forma avaliativa ocorre quando a OAB utiliza esse exame como instrumento de avaliação qualitativa dos cursos jurídicos ao outorgar o selo OAB Recomenda a cursos cujos alunos obtiveram bom desempenho (ORDEM..., 2018). Contrariando a finalidade desta competência o atual presidente da OAB/RS, Ricardo Breier, mencionou recentemente que "O Exame de Ordem foi criado em 1994 e teve um único objetivo: identificar aqueles cursos com menor índice de capacitação, com precariedade no ensino jurídico, não dando condições mínimas para que aquele que frequentasse o curso pudesse ter uma formação adequada. A importância do Exame de Ordem decorre justamente disso, porque não temos um Ministério da Educação que fiscalize esses cursos, muito pelo contrário, cada vez mais são abertos cursos de faculdades de Direito, independentemente de uma análise profunda da sua qualificação ou da abertura do seu quadro docente, da sua biblioteca etc." (ORDEM..., 2019). Não se quer dizer, entretanto, que a universidade não deve se preocupar com a qualidade de seus cursos, mas é necessário primeiro “[...] adjetivar a qualidade - qualificá-la como boa ou má. Ela só será boa, de verdade, se estiver ligada a uma vida digna, construída com base em princípios éticos." (RIOS apud SANTANA, 2007, contracapa, grifo da autora).

${ }^{5}$ Pesquisa realizada pelo grupo de pesquisa Educação e Direito na Sociedade Brasileira Contemporânea, ao analisar a aplicação do Exame de Ordem, verifica que as questões cobradas em regra decorrem da reprodução de artigos de leis e cuja resolução depende unicamente da mera memorização. A pesquisa conclui que mesmo que os candidatos consigam ser aprovados em exames de admissão, os egressos dos cursos jurídicos são avaliados por questões inúteis para o exercício da advocacia, aspecto que demonstra que o equívoco de compreensão está na forma avaliativa proposta pela Ordem. Os argumentos para tal conclusão podem ser encontrados na obra resultante da pesquisa citada, Exame de Ordem - uma visão crítica (TAGLIAVINI, 2010). Em pesquisa mais recente o referido grupo menciona que $75,75 \%$ das questões do Exame 2009/3 e 83\% do IX Exame Unificado, realizado em 2012, foram baseadas na norma jurídica; as questões que exigem memorização da norma ficaram em 57,25\% no Exame 2009/3 e 61\% no IX Exame. Em relação ao primeiro aspecto, conclui que "Houve até um acréscimo em relação ao conhecimento da norma, que continua absoluta em relação à doutrina, jurisprudência, princípios gerais do direito e costumes." Quanto ao aspecto memorização, esclarece que "Ao contrário das promessas da direção federal da Ordem e das expectativas dos educadores, o Exame atual [IX Exame] exigiu ainda mais memorização da norma que o anterior." (TAGLIAVINI, 2013, p.14). Tais dados são apresentados discriminadamente na referida obra. 
Por tais razões é que se pode falar em uma preocupação de abordagem consistente na defesa de outro olhar para o ensino jurídico, ou seja, recolocar o Direito como um curso humanístico. Um curso que não se preocupe unicamente com a aprendizagem do Direito positivado, mas tenha uma preocupação mais abrangente com a própria condição humana, com as relações sociais e com a concretização dos princípios e direitos assegurados na Constituição da República. Enfim, como será abordado posteriormente, com a formação do sujeito para que ele tenha autonomia para a concretização de uma vida digna.

\section{O pensamento humano, o saber e o ensino jurídico}

Em uma abordagem cujo debate central é o ensino jurídico e a formação do bacharel em Direito na perspectiva de compreendê-la como possibilidade de constituição do homem ${ }^{6}$, de seu mundo e da constituição política da sociedade/humanidade, não se pode distanciar da compreensão que envolve o sistema jurídico e social e a contribuição do ensino universitário para a compreensão de relações humanas adequadas para uma existência digna. É neste sentido que, antes de pressupor que a suposta atual crise do ensino jurídico decorra apenas de questões pedagógicas, deve-se partir do olhar epistemológico da área como possibilidade de concretização de perspectivas presentes nas Diretrizes Curriculares Nacionais - DCN (BRASIL, 2004) dos cursos de graduação em Direito ${ }^{7}$. Se existe uma crise no ensino é necessário buscar compreender os fundamentos desta crise e não somente aceitar como verdadeira a hipótese de que se trate apenas de problemas de ensino. É necessária a análise do contexto histórico que ocasionou a atual crise e que, aparentemente, é apontado apenas como uma incapacidade de formar bons aplicadores do Direito ${ }^{8}$, numa clara

\footnotetext{
${ }^{6}$ No decorrer do texto utilizam-se as expressões homem e homens. Utiliza-se tais expressões para designar a espécie humana: homens e mulheres; crianças e adultos; homo e heteroafetividade, enfim, todos concretamente situados para exercerem a cidadania e considerados detentores de deveres na alteridade e portadores de direitos humanos. Em nenhum dos casos se faz distinção de gênero neste artigo.

${ }^{7}$ As Diretrizes Curriculares Nacionais (DCN) do Curso de Graduação em Direito (Brasil, 2004) preveem que o egresso dos cursos jurídicos tenham adquirido as seguintes competências: domínio de conceitos e da terminologia jurídica, da capacidade de argumentação, interpretação e valorização dos fenômenos jurídicos e sociais, capacidade de análise, sólida formação geral, humanística e axiológica aliada à capacidade crítico-reflexiva para que, no exercício profissional, contribua para a prestação da justiça e o desenvolvimento da cidadania. Não se trata, portanto, apenas da aplicação do Direito formal, mas de uma concepção ampliada de atuação para a concretização do bem-estar social através da atuação jurídica.

${ }^{8} \mathrm{O}$ presidente da $\mathrm{OAB} / \mathrm{RS}$, Ricardo Breier, entende que "O modelo que está posto hoje busca as condições mínimas para um bacharel ter os conhecimentos basilares para iniciar sua carreira e, consequentemente, a Ordem deve chancelar se aquela faculdade de Direito deu as condições necessárias para seu funcionamento. Entendo que não caberia só à Ordem fazer isso. Se tivéssemos o MEC mais atuante e fiscalizador, teríamos mais sucesso em evitar a abertura de tantos cursos de Direito pelo país a todo momento, aumentando a expectativa de muitas pessoas em lugares de ensino que não dão as mínimas condições para que possam se tornar bacharéis e, consequentemente, advogados. [...]" (ORDEM..., 2019).
} 
orientação para a capacitação instrumental aplicativa. Não se trata, portanto, de apenas olhar aspectos pedagógicos como algo acoplado ao ensino do Direito e responsável pela crise de seu ensino. É importante considerar as diferentes inter-relações que se estabelecem entre o campo de constituição do saber e o campo de sua comunicação, o espaço pedagógico. A necessidade de diálogo entre as duas perspectivas apontadas para concretizar um Direito que tenha uma utilidade para a vida e para o bem comum pressupõe o aprofundamento o campo epistemológico da área.

Embora atualmente o Estado e a Ordem dos Advogados do Brasil (OAB) tenham, por força legal, o poder de dizer o que significa formar um bacharel, não se pode ficar em silêncio diante de imposição de uma lógica de gabinete. O controle exercido por esses órgãos não indica a melhor formação, funda-se em um caráter reducionista da aprendizagem, se transformando em questão de poder, não de educação. Indica que o Estado, após ter se apoderado do controle dos rumos da educação, demonstra não ter a capacidade e perde sua legitimidade para dizer qual é a formação necessária para o indivíduo viver em sociedade. O controle exercido por essas instituições e sua repercussão no ensino é um campo de análise que não pode ser descartado de qualquer interpretação que se faça da realidade, mesmo que partindo de pressupostos ideais, já que pressupõe a dicotomia entre o olhar do filósofo e o olhar do jurista. Para analisar esta distinção, é pertinente fazer uma análise da História da Filosofia, como o faz Hegel (2004), para tentar compreender a importância do pensamento na formação da humanidade.

Essa formação pressupõe a análise de questões que não dizem respeito somente a avaliação de egressos e implicam diretamente a própria concepção de Direito e de ensino. Tais questões implicam ir mais a fundo no estudo do ensino jurídico, partindo da compreensão da aprendizagem e olhando para a formação do egresso, no mínimo, a partir dessas duas perspectivas. Seguindo as premissas colocadas por Marques,

Em sua generalidade, os debates sobre educação permanecem [...] adstritos ao diagnóstico dos problemas, ao oferecimento de recomendações sobre questões fundamentalmente administrativas, ou à análise de experiências episódicas, denominadas alternativas por seu caráter setorial e limitado por condições muito peculiares, à guisa de experimentos. Embora se avancem direcionamentos teóricos significativos, as questões permanecem, regra geral, como que suspensas no ar e à mercê de enfoques desde o início estreitados e insulados, quando muito apontando para as exigências da multidisciplinaridade, o que, em última análise, significaria remendar o roto, tentar recuperar a unidade do objeto fragmentado de forma irrecuperável nas ciências atomizadas. (MARQUES, 1988, p. 7).

O alerta feito por Marques, agora relacionado à análise que observa questões que envolvem os cursos jurídicos de graduação, parece não ter eco que possibilite a compreensão distinta do saber jurídico e da qualificação do ensino jurídico na perspectiva que se apresenta. Se considerarmos adequado apontar que historicamente existem problemas no ensino jurídico, seria importante 
verificar se o problema está na prática docente jurídica ou é questão de fundamento do conhecimento.

O aspecto peculiar dessa observação decorre, talvez, da dificuldade de transformação do status quo do ensino jurídico, já que as tradições terminam por conservar o ideário por alguma razão que pode ser a incapacidade de reflexão, de modo que as práticas de ensino permanecem imutáveis. Embora se façam diagnósticos e se apontem alternativas que normalmente têm relacionado tal crise à condução da didática do ensino, as propostas resultantes aparentemente não são suficientes para mudar a prática enraizada nas instituições de ensino, apontando, em regra, que o problema está nas práticas docentes. Esse resultado é fundado em afirmações de que as práticas de ensino não têm conseguido melhorar os resultados do desempenho que os estudantes têm em exames de controle citados acima, apresentando, portanto, os baixos resultados aferidos pelos órgãos de controle. É necessário, todavia, refletir a respeito do ensino, da aprendizagem e da epistemologia da área para verificar onde está o possível problema, se na pedagogia empregada, no próprio objeto do ensino jurídico ou trata-se de problema de aprendizagem da atual geração de estudantes.

Mario Osorio Marques, na introdução da obra Conhecimento e Educação, indica caminhos de reflexão sobre os questionamentos postos também para o ensino jurídico, ao ligar a educação ao suporte da vida humana em sociedade para a produção das suas condições de existência. Mario Osorio Marques (1988) afirma que antes de pensar a educação, é necessário pensar fontalmente ${ }^{9}$ saber, já que o conhecimento somente existe como conhecimento dos sujeitos históricos coletivos. Essa concepção ganha respaldo da teoria histórico-cultural de Vygotsky (2008) para explicar como avançamos no conhecimento e possibilita uma perspectiva de análise do caminho percorrido para propor mudanças no que se refere aos saberes necessários ao ensino jurídico e à constituição desse pensamento.

Essa percepção chama a atenção para a dualidade que deve ser superada, entre o saber vulgar e o erudito, e aponta a necessidade de resgatar a unidade do saber humano emancipatório na universidade, o que se faz através do estudo do desenvolvimento histórico-filosófico do conhecimento humano. A incapacidade de concretização deste ideário decorre da própria incapacidade humana de compreender o que seja humanidade e responsabilizar-se pela emancipação humana. Pode ser por desconhecimento de seus fundamentos e de sua essência, bem como da incapacidade dominante de debater a relação epistemológica e a prática pedagógica. A falta de autonomia, no caso do Direito, pode ser imputada ao senso erudito da epistemologia jurídica, a qual propõe o que é ciência e estabelece sua objetividade. A compreensão do caráter do

\footnotetext{
${ }^{9}$ Implica compreender a fonte do saber, seus fundamentos e as implicações e finalidades de seu ensino, não como mera instrumentalização, mas em sua característica emancipatória e estruturante da sociedade e das relações humanas.
} 
saber jurídico diz muito do ensinar e de intervir, talvez pela incapacidade de diálogo com o outro e com a própria compreensão de mundo, sendo adequado buscar o fundamento da relação entre epistemologia e prática pedagógica, como apontam Maldaner (2006) e Fensterseifer (2009a, 2009b).

Mario Osorio Marques, ao discorrer sobre a relação dos saberes de professores e de alunos nas relações da sala de aula, menciona uma resposta provisória: a "[...] concepção de educação como interlocução de saberes: os saberes sobre o educar e os saberes que, na educação, se comunicam e reconstroem na qualidade de os novos saberes da aprendizagem" (MARQUES, 1996, p. 119). O autor aponta a necessidade de superação dos dualismos com que tem trabalhado a razão ocidental, especialmente sob a ótica da bipolaridade entre sujeito e objeto do conhecimento. Para o autor:

Não se faz [...] a educação pelo acesso facilitado a uma pretensa objetividade dos saberes constituídos, nem pelo império de inteligências privilegiadas sobre os destinos do mundo, mas pela interlocução dos saberes que buscam justificar-se numa comunidade de livre-conversação entre iguais, ou na força argumentativa de diversas pretensões de validade. (MARQUES, 1996, p. 120).

É oportuno, portanto, analisar, com Mario Osorio Marques (1996, p. 120-121), “[...] de que saberes se tece a aprendizagem mediada pela docência em sala de aula”. É importante atentar que

[...] os saberes que, em interlocução, se reconstroem na aprendizagem, saberes dos professores e saberes dos alunos, são saberes em anterioridade constituídos. Não se constroem eles a partir do nada, não se inventam simplesmente, mas se reconstroem numa desmontagem e recuperação de modo novo, o modo justamente da aprendizagem. (MARQUES, 1996, p. 121).

Essa afirmação nos leva a considerar a interpretação de Benjamin que enuncia o foco do olhar do anjo da história. O desenvolvimento histórico da humanidade deve ser considerado quando estamos fazendo proposições de ensino. O ensino não se faz sem considerarmos a construção histórica de saberes, bem como os impactos que tal construção tem gerado para a humanidade e seu mundo.

Há um quadro de Klee intitulado Angelus Novus. Representa um anjo que parece preparar-se para se afastar de qualquer coisa que olha fixamente. Tem os olhos esbugalhados, a boca escancarada e as asas abertas. $\mathrm{O}$ anjo da história deve ter esse aspecto. Voltou o rosto para o passado. A cadeia de fatos que aparece diante dos nossos olhos é para ele uma catástrofe sem fim, que incessantemente acumula ruínas sobre ruínas e lhas lança aos pés. Ele gostaria de parar para acordar os mortos e reconstituir, a partir de seus fragmentos, aquilo que foi destruído. Mas do paraíso sopra um vendaval que se enrodilha nas suas asas, e que é tão forte que o anjo já não as consegue fechar. Esse vendaval arrasta-o imparavelmente para o futuro, a que ele volta as costas, enquanto o monte de ruínas à sua frente cresce até o céu. Aquilo a que chamamos de progresso é este vendaval. (BENJAMIN, 2013, contracapa). 
Tal pensamento, ao menos, nos demonstra que é necessário ter em mente que os objetos da criação humana, embora apresentadas como progresso da humanidade, não são suficientes para garantir um mundo melhor. E que na esfera jurídica sua tecnologia tem servido apenas para garantir a propriedade dos resultados deste progresso sem significar vida digna para toda a humanidade. Por outro lado, indica que é necessário olhar para o passado também em relação ao ensino jurídico, já que há equívocos que são vistos, mas para os quais as soluções apontadas têm sido incipientes.

Pensar o ensino jurídico implica pensar a universidade e o contexto histórico como é organizado, debatido e refletido o conhecimento humano em seu interior. Implica pensar a própria aprendizagem no contexto da concreta configuração do ensino. Ao analisar a aprendizagem humana pode-se conceber apenas a aprendizagem individual/singularizada do homem ou seria recomendável analisar tal contexto no mundo da vida a partir de uma clareza de finalidade que se busca com a própria formação e perpetuação do conhecimento humano?

Ter clareza acerca dos objetivos do ensino e da educação na universidade é um pressuposto para quem se propõe a ensinar. Uma ação humana transcendente e intersubjetiva é necessária para construir as condições de ensino de modo que, como contrapartida, possamos ter uma aprendizagem que também se molde no debate intersubjetivo e transcendente.

O entendimento da aprendizagem a que chegamos a supõe concreta configuração, reconstrução autotranscendente do ser homem singularizado entre os homens. Dão-se as condições gerais da aprendizagem no mundo da vida enquanto horizonte de sentidos, pano de fundo em cuja facticidade habitam os dados empíricos do cotidiano vivido e do qual irradiam a cultura, a sociedade e a personalidade distintiva de cada um. E nessa constituição do homem genérico se insere a singularização do sujeito na estruturação simbólica da palavra em que se pode constituir ele como socialmente competente e singularmente autônomo, criativo, atento às muitas possibilidades em aberto, sem fechar-se no isolamento narcísico ou no exclusivismo das posições inamovíveis. (MARQUES, 1996, p. 121).

Tal entendimento nos mostra a necessidade latente de debatermos o ensino e a aprendizagem considerando que em qualquer área não se faz universidade apenas de conteúdo, mas está implícita a necessidade de considerarmos outros fatores que podem contribuir para a transformação do mundo e das relações sociais na perspectiva da concretização de uma possível emancipação ${ }^{10}$ humana. Talvez seja neste sentido que Mario Osorio Marques (2003, p. 10) proponha “[...] a ênfase na sala de aula aos temas transversais da democracia, da política e da ética”. O autor explica:

Em nossa opção por esses temas transversais, além de considerá-los aptos a articular áreas distintas de saber na ação conjugada de uma equipe de educadores e desde enfoques epistêmicos diferençados e específicas

\footnotetext{
${ }^{10}$ Considerada aqui como o esclarecimento, a saída do homem de sua menoridade, como debatem Adorno e Horkheimer (1985). A respeito, a próxima nota de referência (nota 10) deste artigo.
} 
vivências socioculturais, privilegiamos o paradigma ético, político e democrático de valores que se façam presentes nas relações pedagógicas, nas atitudes e nos comportamentos, na igualdade das condições de continuada interlocução propiciada pela coerente organização da escola. Busca-se, em suma, superar o moralismo das relações pedagógicas através de normas e regras, códigos de conduta, direitos e deveres préestabelecidos, que apenas sustentam as ações repressoras e legitimam a exclusão social. E busca-se superar as distâncias das disciplinas escolares entre si e delas com o mundo da vida e com os processos que levem às aprendizagens das competências indispensáveis ao viver juntos numa sociedade de iguais na condição de sujeitos singularmente autônomos e socialmente competentes. (MARQUES, 2003, p. 10).

Tal abordagem oferece subsídios para pensarmos o ensino jurídico na educação superior a partir dos aspectos que nos conduzam a pensar como é possível construir uma perspectiva onde a formação não seja apenas decorrente de um conjunto de disciplinas desencadeadas em um currículo disciplinar de conteúdos isolados. Tal perspectiva pode nos alertar de que a análise disciplinar deve conduzir à redução do isolamento de áreas para que a formação seja desencadeada a partir de conteúdos que se relacionem durante a formação e que tenham um encadeamento lógico durante o tempo de formação. Neste aspecto, a transversalidade reclama também a análise da historicidade e a reflexão necessária.

O anjo da história (BENJAMIN, 2013) nos alerta para a necessidade de recordar o passado, e nos indica que a constituição de uma proposta de ensino com caráter humanista deve ser enfrentada. Tal enfrentamento consiste no espaço de reflexão sobre questões e valores a partir do necessário filosofar como possibilidade de construção do conhecimento.

Considerando que o ensino pragmático reduzido à aplicação de técnicas jurídicas não satisfaz às necessidades da sociedade, que a modernidade fez promessas que não conseguiu cumprir e que o ensino para a aplicação da técnica não é suficiente para recuperar tais promessas, torna-se imprescindível refletir a respeito. E, para esta reflexão, temos que nos afastar da realidade para sobre ela refletir. O pragmatismo atual, ao buscar sua satisfação no ensino, ocasiona o individualismo exacerbado. Dominar a técnica jurídica para aperfeiçoar os meios próprios de sobrevivência, de sucesso profissional e de acumulação patrimonial, esta tem sido a finalidade objetivada pela formação. A satisfação consiste no alcance dos meios de concretização de interesses individuais apenas. Tal concretização, via de regra, ocorre sem que se pense em qualquer impacto sobre a sociedade coletiva, mas como satisfação individualizada.

Percebemos, portanto, que falar em crise do ensino jurídico implica um olhar mais profundo sobre a formação cultural e a preocupação em pensar sobre a realidade e tentar construir um mundo melhor. Pensar a realidade é filosofar, mas implica conhecer o próprio pensamento. Todavia, “[...] 
para que um povo filosofe, convém que já tenha alcançado um certo grau de cultura intelectual" (HEGEL, 2004, p. 88). Como afirma o filósofo,

Tem que ter havido preocupação com as necessidades da vida, o temor das paixões tem que ter desaparecido; deve ter-se extinguido o simples interesse finito do sujeito, e a consciência tem que haver se desenvolvido muito, a fim de mostrar interesse em objetos universais. A filosofia é um tornar livre (daí a necessidade da filosofia). Pode-se considerá-la como um luxo; pois o luxo é a satisfação de alguma coisa que não corresponde à necessidade imediata; sem dúvida, quanto a isto, é supérflua. Porém, trata-se do que se chama necessário. Por parte do espírito pensante deve-se considerar a filosofia como o mais necessário. (HEGEL, 2004, p. 88).

Se acima mencionamos a necessidade de tratamento transversal de temas e, portanto, de disciplinas, temos que pressupor tal transversalidade possível agregando os fenômenos do mundo da vida. Trabalhar de tal forma ganha sentido quando tal iniciativa tem a intenção de levar o sujeito à reflexão filosófica. É neste sentido que se relaciona o pensamento de Mario Osorio Marques ao de Hegel e se afirma que a universidade deve proporcionar a volta ao pensar. A universidade não deve orientar seu fazer formativo ao pragmatismo do ensino da técnica e de sua aplicação. Acima de tudo, deve possibilitar o questionamento da realidade posta do mundo da vida e a retirada para a reflexão.

A análise que faz Mario Osorio Marques (2002), na obra Educação nas Ciências: interlocução e complementaridade, demonstra que são necessárias a interlocução e a complementaridade, leva-nos a compreender que é preciso transcender a fragmentação, as classificações e a simplificação, e nos induz a olhar para a crise e propor a reflexão.

A crise do ensino jurídico é produzida pelo desestímulo ao pensamento e ao esclarecimento $^{11}$. A finalidade do ensino jurídico não tem sido propriamente produzir uma evolução humanitária da sociedade. Existem interesses ${ }^{12}$ que necessitam do jurídico para permanecerem intocáveis numa sociedade planetária desigual, onde o pensamento reflexivo parece desnecessário. O pensamento, neste momento secular, é apenas uma condição imperceptível de uma engrenagem movida inconscientemente pelo modismo consumista que tem levado multidões a trabalharem por

\footnotetext{
${ }^{11}$ Não se pode admitir que o ensino jurídico deixe de lado a compreensão de que o esclarecimento humano reflete a autonomia. Assim, o ensino superior deve conduzir a ele. Como afirma Immanuel Kant, o "'Esclarecimento" (Aufklärung) significa a saída do homem de sua menoridade, da qual o culpado é ele próprio. A menoridade é a incapacidade de fazer uso de seu entendimento sem a direção de outro indivíduo. $\mathrm{O}$ homem é o próprio culpado dessa menoridade se a sua causa não estiver na ausência de entendimento, mas na ausência de decisão e coragem de servir-se de si mesmo sem a direção de outrem. Sapere aude! Tem a ousadia de fazer uso de teu próprio entendimento - tal é o lema do Esclarecimento (Aufklärung)." (KANT, 2011, p. 115, grifos do autor).

${ }^{12}$ Tal entendimento não é recente, basta analisar a produção legislativa no Brasil e os conflitos de interesses públicos e privados dela decorrente. Roberto Aguiar (2014) menciona tais interesses na obra Direito, Poder e Opressão, quando produz uma visão que reflete a crença na emancipação humana através do ensino jurídico.
} 
um modelo econômico que, como resultado da modernidade, apenas possibilita que os resultados econômicos sejam globalizados e distribuídos entre uma minoria que detém a produção.

É necessário, portanto, provocar o pensamento para a preocupação com a humanidade resultante da modernidade de modo que seus resultados sejam distribuídos de forma globalizada, de forma que diminuam as distâncias entre os incluídos e os excluídos no planejamento global.

Ao pensarmos o ensino do Direito como uma possível alternativa para a concretização e distribuição dos avanços da modernidade rumo a um tempo pós-moderno, é necessário considerar que a humanidade clama por uma menor desigualdade entre os indivíduos, de forma que é necessário compreendermos a opção pela atual metodologia de ensino que mais parece a produção na fábrica para propor mudanças estruturais e culturais.

Aparentemente o aspecto essencial da crise do ensino jurídico não se afasta da crise maior que é a própria existência do homem. Mario Osorio Marques desenvolve seu pensamento articulando história, memória e experiências vividas. Articular a história, podemos fazê-lo, dialogando com diversos pensadores que durante séculos refletiram sobre o próprio pensamento humano. Essa é a própria condição para o desenvolvimento da universidade e do ensino superior. A reflexão sobre o pensamento e sobre o conhecimento é necessária. Compreender o comportamento humano responsável pela modernidade para alicerçarmos um período pós-moderno ou neomoderno, como menciona Marques (1993, p. 108), para que se tenha uma educação como “[...] alargamento do horizonte cultural, relacional e expressivo, na dinâmica das experiências vividas e na totalidade da aprendizagem da humanidade pelos homens."

O ensino jurídico não pode ser descolado da história do pensamento humano. No campo da formação em Direito, como em qualquer outra área da formação humana, há necessidade de refletirmos sobre o pensamento e sua importância na concretização do mundo humano. Se considerarmos que o mundo humano é a construção efetiva a partir da existência, teremos que levar em consideração que não existe o homem sem o pensamento. Este, todavia, não existe sem a linguagem. A linguagem consiste na possibilidade de compreensão pela atribuição de significados a todos os fenômenos que acontecem e que passam a integrar a existência humana. Assim, pensamos o mundo a partir da possibilidade de significados e sentidos que se tornam possíveis a partir da compreensão da linguagem. Sem a linguagem somos animais sensíveis que não têm condição de atribuir sentido aos sentimentos e a tudo o que rodeia o mundo humano. A existência de um mundo somente é possível porque o homem construiu uma realidade comunicativa, a qual pode ser ilimitadamente ampliada à medida da inteligência humana. $O$ mundo jurídico é uma ampliação dessa realidade comunicativa e ocorre pelo entendimento humano. 
A realidade comunicativa, embora apresente a possibilidade de comunicação quase ilimitada e possa ser compreendida como extensão do corpo e da existência, pode não propiciar a capacidade de reflexão. Neste contexto, embora crie possibilidades, pode inviabilizar a própria existência humana na medida em que a transforma apenas em espécie de alegoria do espetáculo, torna o homem apenas um atômato destituído de capacidade reflexiva. Esse quadro alerta para a necessidade de refletir sobre as questões da educação também no âmbito do Direito. No aspecto do ensino jurídico, é necessário constituir sujeitos pensantes, com capacidade reflexiva e que possam contribuir para a concretização das promessas da modernidade. É evidente que a universidade se afastou de seu mister; cabe agora, retomar o caminho. Esse caminho, consiste em analisar as questões postas no correr da história da humanidade, recuperar a capacidade de pensar, analisar os anseios da humanidade e buscar a concretização de necessidades menos efêmeras que as alçadas ao grau de necessidades fundamentais de consumo.

Tal anseio, implica em rever o papel da universidade e dos cursos jurídicos. Em uma sociedade capitalista na qual o controle decorre de regras jurídicas, administrativas e econômicas terá a universidade força suficiente para garantir uma proposta de formação humana para a humanidade? No próximo tópico abordamos tais aspectos.

\section{Ensino jurídico, lastro humanístico e sociabilidade}

A formação universitária na área jurídica pressupõe um núcleo articulador da formação, dos diferentes momentos, conteúdos, conhecimentos e disciplinas que integram a área. Propor uma perspectiva que procure analisar a formação integral do sujeito a partir da compreensão de mundo, do contexto e das condições em que o egresso do ensino básico adentra no ensino superior é um desafio na sociedade do consumo. É a dimensão humanística que dá sentido ao ensino do Direito em uma universidade. Humanístico no sentido de um conhecimento que não é útil, mas necessário, que mude a mentalidade e que possibilite a autonomia de pensamento. Nesta condição, seria deixar de olhar pelo viés apenas de uma profissão jurídica de advogado, juiz, delegado, entre outras, para compreendê-la como uma grande formação, necessária para a vida em sociedade.

Nessa perspectiva o ensino jurídico teria o potencial de colocar isso em primeiro lugar diante dos outros aspectos, até mesmo como pressuposto para a utilização das técnicas jurídicas e processuais. Mas se não houver uma boa argumentação de forma que se ultrapassem os dados objetivos de uma atuação técnico-jurídica, por exemplo, não se faz nada. O ensino jurídico não é uma matemática pura, a expressão pura dos fatos, é uma interpretação em relação à condição 
humana, aos direitos humanos, à dignidade humana, à constituição da cidadania. ${ }^{13}$ Isso indica que o ensino do Direito deve considerar o outro nas relações humanas. Não se concebe, portanto, o ensino jurídico como uma simples formação para o mercado, como uma técnica jurídica sem uma formação num lastro humanístico, como também não se admite o Direito como um sistema fechado; a vida social é marcada pela incerteza ${ }^{14}$ e a formação deve ser integral e considerar que a profissão e o mercado são facetas integrantes das relações sociais. Não se trata, portanto, de formar alguém que considere imutável a Constituição ${ }^{15}$ (BRASIL, 1988), mas que entenda que a sociedade e os costumes humanos são mutáveis, de forma que a lei segue a mesma lógica, sendo, portanto, capaz de revisá-la para que a sua letra esteja sempre próxima da vida humana. Esse pensamento já foi expresso pelos filósofos iluministas e continua atual:

O fim da instrução não é fazer que os homens admirem uma legislação pronta, mas torná-los capazes de avaliá-la e corrigi-la. Não se trata de submeter cada geração às opiniões bem como às vontades daquela que a precede, porém de esclarecê-las cada vez mais, a fim de que cada uma se torne cada vez mais digna de governar-se por sua própria razão. (CONDORCET, 2008, p. 53).

Ao se considerar a formação jurídica, várias serão as opções articuladas para organizar a estrutura do ensino. O que se defende aqui é que a formação deve extrapolar a ideia conteudista e primar pela priorização de uma abordagem filosófico-humanista que conduza o aluno à reflexão e não somente à mera repetição de conteúdos. $\mathrm{O}$ desenvolvimento, o progresso e a autonomia devem estar presentes, implícitos na formação, como oportunidade de qualificação da vida humana.

Acredita-se que o conhecimento para a autonomia é a linha lógica que deve ser perseguida na formação jurídica. Os cursos universitários devem conduzir os alunos a questionarem a ideia de conhecimento, as verdades postas como verdades absolutas, como se produz o conhecimento e como ele pode transformar as vidas e a própria sociedade. É preciso desmistificar essas ideias para que o sujeito se considere partícipe dessa construção social e para o desenvolvimento humano que vise à constituição de uma sociedade com autonomia para pensar e recriar o Direito, talvez de forma humanamente mais justa e com maior solidariedade.

\footnotetext{
13 Essa abordagem de uma perspectiva humanista, embora não seja garantia de certeza da efetividade, materialidade e concretização dos direitos, compreende que é necessário capacitar o sujeito para o pensar autônomo e crítico-reflexivo, para elevar seu pensamento à condição do outro e ao desenvolvimento de condutas de tolerância nas relações sociais. Consiste em criar condições de fortalecimento do espaço público pela cidadania. ${ }^{14}$ O humano é o caos (CASTORIADIS, 1982), um malabarismo (MLODINOW, 2011; HEISENBERG, 1996).

${ }^{15}$ Embora se fale aqui e até se defenda a ideia de mutabilidade de acordo com as mudanças do mundo da vida, deve-se atentar para o fato de que não se defende a ideia de qualquer alteração constitucional segundo interesses dos grupos que estão no poder, mas mudanças para concretizar o próprio objetivo constitucional em uma República Democrática. Por outro lado, a Constituição da República Federativa do Brasil (BRASIL, 1988), promulgada em 1988, consta, em 18 de outubro de 2018, com 6 Emendas Constitucionais de revisão (previstas no texto original) e 99 outras Emendas Constitucionais, mas deve-se atentar para a ideia de mutabilidade constitucional decorrente da hermenêutica. Os conceitos, os símbolos, as palavras têm sentido e significação alterados no tempo. A respeito refere-se Grau (2017) sobre o processo normativo a partir da lei.
} 
A atualidade capitalista pós-industrial demanda a formação de juristas habilitados a conhecerem os problemas humanos e sociais e com capacidade de enfrentá-los. A universidade deve proporcionar a formação da capacidade de sujeitos preparados para este mundo que se apresenta de forma distinta e que pressupõe indivíduos que tenham uma grande capacidade de inovar: daí a necessidade de formar sua autonomia.

Esta capacidade de inovação depende muito mais de outros conhecimentos, de uma formação mais generalista, do que da memorização e lembrança de conteúdos estudados durante uma formação universitária especialista. Pressupõe, por exemplo, o desenvolvimento da capacidade de analisar e compreender os fenômenos, olhar para a realidade e ser corresponsável com o outro, de compreender e de autonomamente, construir e reconstruir as relações humanas.

Nestas condições, a formação humana concilia a cultura e a técnica, possibilita a formação para a vida em sociedade e para o exercício da profissão, mas não a aparta do viver na comunidade. Esse formar pressupõe que a formação profissional não pode ser apartada do mundo da vida (HABERMAS, 2012; MARQUES, 2006) sob pena de direcionar a compreensão humana da profissão apenas para o sucesso financeiro de uma vida desprovida de humanidade. Tem-se, portanto, uma expectativa de que esta formação desenvolva a capacidade de um olhar para o lastro humanístico que fundamenta o viver em sociedade e que demonstre que o desenvolvimento de qualquer profissão somente tem sentido se acarretar a acumulação de riquezas vitais, não apenas de riquezas materiais e econômicas.

Existe a possibilidade, portanto, de reconhecimento da unidade da realidade e do sentido. A realidade existe, é um fenômeno ao qual o homem atribui significados e sentidos. A proposta de ensino jurídico numa perspectiva humanística provoca a necessidade de repensar o humano a partir da compreensão do projeto humano-social, mas sobretudo analisando que a perspectiva de formação das futuras gerações deve levar em conta que o instrumental técnico é decorrência e tem sentido para a humanidade, de modo que a humanidade não pode correr o risco de ser descartada pela técnica por ela criada. A técnica possibilitou o domínio humano sobre a natureza e as espécies vivas ${ }^{16}$ e seu desenvolvimento e utilização, sempre sob a proteção do econômico, do administrativo e do jurídico, ultrapassa os limites da razoabilidade, sugerindo ser defensável a perspectiva de que é necessário um outro pensamento jurídico, na perspectiva acima mencionada.

Mas não se pode desprezar a ideia de que o ensino jurídico seja uma realidade anteriormente construída. Tal como a realidade científica, o ensino deve olhar para o passado e o faz à medida em

\footnotetext{
${ }^{16}$ Quando se fala em domínio humano sobre a natureza e as espécies vivas está se pensando que entre as espécies vivas está o humano e que, numa sociedade com desigualdade social, o poder econômico destitui alguns da completa fruição dos benefícios da modernidade. Talvez essa possa ser considerada uma das patologias sociais, como bem enuncia Habermas (2012).
} 
que estabelece um espaço de debate interdisciplinar apoiado em uma propedêutica que leve à reflexão autônoma, não apenas como um instrumento de exercício do poder. Nessa dimensão, a formação humanística no Direito deveria se constituir no foco central do ensino jurídico, de forma a agregar a preocupação com o projeto humano-social e sua sociabilidade. Nesta perspectiva,

O conhecimento científico pretende ser sempre a reforma de ilusões, mas pode ele mesmo transformar-se em ilusão se estiver atento unicamente a si mesmo e pode levar a um reino de especialistas indispensáveis à operação da máquina social, destituídos, porém, da tomada de decisões, reduzidos à categoria de executantes mais ou menos respeitados. Semelhante à alienação da subjetividade enclausurada em si mesma é a alienação da objetividade desamparada da presença ativa do sujeito humano. (MARQUES, 1988, p. 23).

A presença humana ativa deve ser consequência da ação formativa que tenha a capacidade de desacomodar o sujeito em sua condição humana e que, além de qualificar para o exercício de uma profissão, sensibilize.

Assim, se volta à ênfase de que não basta uma boa especialização no sistema jurídico e a aposta na racionalidade instrumental. A vida social necessita de sujeitos que compreendam que a finalidade do ensino jurídico é também acomodar as tensões e tornar a vida sociável. É possível, portanto, conduzir à crença na processualidade jurídica como o sustentáculo da sociabilidade à medida que o processo garante a aversão à arbitrariedade humana, pelo menos em tese. Se defronta uma questão de fundo que deve ser debatida para verificar o foco que se deve priorizar no ensino: o conteúdo ou a processualidade para que o Direito seja compreendido como imaginário instituinte da continuidade social.

Nesse contexto apresentado nos últimos parágrafos se pretende defender a ideia de uma formação social e do papel do Direito na inter-relação com a realidade imaginada ${ }^{17}$ bem como a contribuição do ensino jurídico para a sociabilidade humana. A partir da compreensão de que ao atribuir sentido às coisas o homem cria o mundo e transforma seu modo de viver, surge a possibilidade de condicionamento de todas as espécies do planeta à experiência humana, aspecto que passa a determinar as condições da vida.

A evolução possibilita que o humano, preponderando sobre as outras espécies, pelo conhecimento construa as explicações teóricas para tudo, chegando à modernidade com a capacidade de estabelecer verdades unicamente atribuídas à sua capacidade racional. Cria teorias para explicar sistemas fechados ${ }^{18}$ que alcançam determinado fim e acredita que é possível um fim

\footnotetext{
${ }^{17}$ Uma realidade imaginada é uma criação humana e, tradicionalmente, imposta universalmente como verdade. A realidade imaginada ganha importância quando se verifica que é fundada na racionalidade humana e se constitui a partir da sofisticação de uma ideia imaginada que tem a capacidade instituinte de moldar o futuro porque as pessoas acreditam nela.

${ }^{18}$ Pode-se dizer que o sistema jurídico termina sendo um sistema fechado que tem validade por si mesmo e que passa a ter validade unicamente como sistema, de forma que se deixam de lado as finalidades de sua instituição,
} 
determinável a ser empiricamente comprovado através da ciência moderna, a qual assegura tais verdades. Essa compreensão, embora passível de controvérsias, como a decorrente do princípio da incerteza de Heisenberg, indica a inadequação de não tentar olhar de forma distinta as certezas. Pode-se fazer isso citando o próprio Heisenberg quando menciona o maior feito de Cristóvão Colombo, segundo seu entendimento: “[...] foi a decisão de sair das regiões conhecidas do mundo e navegar para o Ocidente, até muito além do ponto a partir do qual seus suprimentos poderiam levá-lo de volta para casa." Significa que é necessário não acreditar cegamente naquilo que está sendo posto como verdade única. Como diz o autor, “[...] Também na ciência, é impossível abrir novos campos se não se estiver disposto a deixar o ancoradouro seguro da doutrina aceita e enfrentar o perigo de um arriscado salto à frente em direção ao vazio.” (HEISENBERG, 1996, p. 87).

Observando as teorias sobre a evolução humana desde os primórdios e aceitando a evolução como uma verdade possível, pensa-se que é necessário compreender o papel do imaginário na formulação das verdades. Descarta-se admitir um querer sem imaginário. E não há imaginário sem pensamento e simbólico. É adequado, portanto, dizer que não há uma certeza; se houvesse, não teria sentido ficarmos desenvolvendo teorias e provocando proposições. As teorias existem para tentar explicar os acontecimentos, mas é possível somente ter uma certeza quando se olha para o passado e se comprova os efeitos pretéritos que teve determinada conduta ou ação, como demonstra o anjo da história. Mas isso não indica uma certeza quanto aos fatos futuros, apenas indica uma possibilidade.

É por esta razão, por considerar a vida algo desconhecido, que a formação deve buscar a constituição da autonomia do sujeito. Como sequer se sabe o que é a vida, apenas se pode compreendê-la como o espaço da liberdade, da possibilidade de ação, da práxis; não é possível educar como se já estivesse determinado aquilo que vai ser a vida. Por essa razão é que se pode falar apenas em formação para a autonomia, nos moldes apresentados por Hannah Arendt (2014), em ensino jurídico como formação para a autonomia de ação na sociedade. Significa que diante da vida o sujeito passa a ter uma posição autônoma. ${ }^{19}$

Com o Direito não é diferente. Se for considerado uma ciência, parte-se do pressuposto que ele não pode ser considerado um campo exato, como também pode ter compreensão distinta de uma

de modo que o Estado passa a se preocupar com a validade dentro do sistema e não com a concretização das finalidades a que ele deveria servir. Neste contexto, pode-se dizer que talvez exista uma grande fragilidade no próprio ensino jurídico e na sua avaliação pelos sistemas estatal e institucional da $\mathrm{OAB}$, os quais preocupam-se com o conhecimento do sistema fechado e não com sua utilização para a concretização do interesse público para a satisfação dos interesses da sociedade em geral.

19 A autonomia humana e da sociedade são, afirma Castoriadis, a principal aspiração que ultrapassa as singularidades da constituição pessoal, a única publicamente defensável com lucidez e coerência. A relação é dupla, devendo existir a qualquer época e circunstância, como também inerente ao homem e à história. "[...] como a consciência, o objetivo de autonomia é o destino do homem, porque, presente, desde o início, ela constitui a história mais do que é constituída por ela.”(CASTORIADIS, 1982, p. 121). 
ciência social aplicada. Ele refere-se à conduta humana na sociedade. Pode-se dizer que se trata do campo das humanidades, já que embora seja distinto da Ética e da Moral, poderia o jurídico conduzir a conduta humana a elas. Sem abordar esse aspecto agora, volta-se ao campo da compreensão do que é o Direito para compreender como se dá a formação humana neste campo.

O ensino jurídico pretende apenas concretizar uma formação técnica e ou, na perspectiva da autonomia, pode ser compreendido como meio para a humanidade e a sociabilidade? A formação possível é aquela alimentada pelo imaginário.

Cornelius Castoriadis lança algumas luzes para o fortalecimento da compreensão do imaginário. Aspecto essencial é compreender que o mundo é criação humana ${ }^{20}$ sustentada pelo imaginário que necessita da linguagem como instituição. Esta compreensão é sustentável na ideia de que é a imaginação a responsável por traçar possibilidades que depois serão as balizas das condutas humanas. A imaginação é que possibilita deixar de lado a certeza para torná-la aventura no desbravamento do desconhecido. Por outro lado, indica que a saída daquilo que é estabelecido pelo Direito como razoável, tem na incerteza o papel de condutora do destino.

A formação humana contribuindo para o desenvolvimento da autonomia, é compreendida como uma finalidade exterior ao próprio conteúdo do Direito, tendo a ver com as relações humanas. Nesse viés, o ensino jurídico não pode ser compreendido apenas como a capacitação técnica do outro, mas deve preocupar-se com a constituição de um imaginário autônomo capaz de ter na incerteza o princípio da vida. $\mathrm{O}$ ensino jurídico deve resgatar o papel formador da autonomia para a práxis ${ }^{21}$ no sentido proposto por Castoriadis. Como diz o autor, "[...] Existe na praxis um por fazer, mas esse por fazer é específico: é precisamente o desenvolvimento da autonomia do outro" (CASTORIADIS, 1982, p. 94).

$\mathrm{O}$ autor alerta que

A praxis não pode ser reduzida a um esquema de fins e meios. O esquema do fim e dos meios pertence precisamente à atividade técnica, pois esta tem relação com um verdadeiro fim, um fim que é um fim, um fim finito e definido que pode ser estabelecido como um resultado necessário ou provável, em vista do qual a escolha dos meios se reduz a uma questão de cálculo mais ou menos exato; com este fim, os meios não têm nenhuma relação interna, simplesmente uma relação de causa e efeito. (CASTORIADIS, 1982, p. 94-95).

\footnotetext{
${ }^{20} \mathrm{O}$ mundo é criação humana pois somente é possível dizê-lo a partir do suporte simbólico expressado por palavras e pelo pensamento. O mundo é, portanto, resultado da imaginação humana e ganha status universal com a palavra. "A instituição da sociedade é toda vez instituição de um magma de significações imaginárias sociais, que podemos e devemos denominar um mundo de significações." (CASTORIADIS, 1982, p. 404).

${ }^{21}$ A práxis, para Castoriadis, é o "[...] fazer no qual o outro ou os outros são visados como seres autônomos e considerados como o agente essencial do desenvolvimento de sua própria autonomia." (CASTORIADIS, 1982, p. 94). Entende-se, portanto, que essa práxis é ação a partir do abstrato. Não se trata de apenas compreender a autonomia, mas exercê-la.
} 
Contrariamente, na formação o desenvolvimento da autonomia é uma constante que pode perdurar durante toda a vida do sujeito. Na formação jurídica vai se considerar que deverá fornecer meios para que o sujeito consiga desenvolver sua autonomia, mas não tem um fim determinado. Se quer um sujeito que possa interagir livremente nessa sociedade exercendo sua autonomia, mas respeitando a autonomia dos outros. Para Castoriadis a autonomia dos outros é um começo. É neste sentido que se pode considerar o ensino jurídico uma práxis pela qual pode-se desenvolver a autonomia do sujeito não apenas para a aplicação técnica, mas como sociabilidade humana. Para isso, volta-se à formação para o pensar descomprometido com um fim único, ao imaginário criador, como um desenvolvimento da autonomia.

Existe relação interna entre o que é visado (o desenvolvimento da autonomia) e aquilo por que ele é visado (o exercício desta autonomia), são dois momentos de um processo; finalmente, desenvolvendo num contexto concreto que a condiciona e devendo levar em consideração a rede complexa de relações causais que percorrem seu domínio, a praxis jamais pode reduzir a escolha de sua maneira de operar a um simples cálculo; não que este fosse muito complicado, mas porque, por definição, deixaria escapar o fator principal - a autonomia. (CASTORIADIS, 1982, p. 95).

Castoriadis indica que não se pode correr o risco de reduzir a aprendizagem a uma técnica a ser aplicada; não se pode aceitar a proposta de Direito como lei única a ser aplicada; não se pode aceitar a ideia de instrumentalização do Direito para o atendimento de interesses de grupos apenas. Neste sentido, o ensino jurídico deve compreender uma abertura para o mundo, mas para isso é necessária a compreensão de mundo. É condição necessária o imaginário com autonomia. Como menciona o autor,

A praxis é, por certo, uma atividade consciente, só podendo existir na lucidez; mas ela é diferente da aplicação de um saber preliminar [...]. Ela se apoia em um saber, mas este é sempre fragmentário e provisório. É fragmentário, porque não pode haver teoria exaustiva do homem e da história; ele é provisório, porque a própria praxis faz surgir constantemente um novo saber, porque ela faz o mundo girar ao mesmo tempo singular e universal. É por isso que suas relações com a teoria, a verdadeira teoria corretamente concebida, são infinitamente mais íntimas e mais profundas do que as de qualquer técnica ou prática "rigorosamente racional" para a qual a teoria não passa de um código de prescrições mortas não podendo nunca encontrar o sentido daquilo que maneja. (CASTORIADIS, 1982, p. 95, grifos do autor).

Deste apanhado pode-se deduzir que a ideia de formação apresenta a perspectiva de elucidação da mente, ou seja, apresenta a aprendizagem como a possibilidade de desenvolvimento da autonomia de pensamento. É uma perspectiva a partir da qual, conscientemente, se sabe o que faz e por que faz.

Este viés indica que é necessário pensar a linguagem e a interpretação quando se fala em formação humana, já que constituem, em essência, a base da humanidade. Na esteira de Castoriadis, portanto, compreende-se que quando se pensa a formação jurídica não se pode incorrer no equívoco 
de apresentar uma solução à formação. Quando muito, a partir da compreensão dos consensos, será possível propor a ideia de desenvolvimento da autonomia a partir do ensino. Mas, por outro lado, esta perspectiva indica ser um equívoco aferir o grau de formação através de exames de memorização de conteúdo. A formação, portanto, deve se dar para o mundo na perspectiva da sociabilidade e da autonomia, para a ação consciente numa sociedade imaginada.

Aceita a ideia de que a formação jurídica deve conduzir à autonomia do sujeito, pode-se, portanto, afastar uma natureza humana que estabeleça o sentido da vida. Trata-se de criação social que deve ser conduzida pela formação, já que "[...] o homem não nasce trazendo consigo o sentido definido de sua vida. O máximo de consumo, de poderio ou de santidade não são objetivos inatos à criança, é a cultura na qual crescerá, que lhe ensinará que ela tem 'necessidade' disso." (CASTORIADIS, 1982, p. 37).

Assim como Castoriadis se refere ao marxismo para fazer sua crítica, não se pode dizer que qualquer teoria indique o segredo da história passada e presente, muito menos da futura. Isso indica que se podem fazer algumas conjecturas para especular a respeito de uma metodologia adequada a evitar a formação míope das futuras gerações. Não se pode, entretanto, tê-la como a resposta definitiva, embora possa ser aceitável do ponto de vista da razoabilidade.

\section{Conclusão}

A guisa de conclusão pode-se dizer que se percebe grande equívoco na forma como se ensina o Direito e se avalia o ensino. A instituição do sistema avaliativo dos cursos a partir da atuação da $\mathrm{OAB}$, por exemplo, gera uma preocupação voltada a aprovação dos egressos no Exame de Ordem e pode frustrar os objetivos de formação integral. Se o exame de proficiência é estruturado basicamente em questões de memorização, mesmo sem utilidade prática para o exercício da advocacia, isso demonstra que os cursos jurídicos podem ter uma preocupação com o enfrentamento do Exame e não com a formação integral. Neste contexto, os cursos jurídicos podem terminar pautado sua atuação pela transmissão e memorização de um conjunto de conteúdos programáticos voltados ao manuseio dos instrumentos legais dentro de um sistema jurídico fechado. Embora se fale em democracia, direitos humanos e cidadania, entre outros vários aspectos, o ensino termina sendo avaliado externamente apenas pela capacidade de aplicação dos instrumentos jurídicos e de conhecimento da legislação em vigor.

Sob outro aspecto, esta avaliação busca aferir não a autonomia do sujeito para o atendimento do interesse maior da sociedade, mas o conhecimento do sujeito acerca do Direito positivado, 
normalmente reprimindo qualquer interpretação distinta da lei, aspecto fartamente demonstrado nas pesquisas citadas. Neste sentido ocorre uma espécie de direcionamento do entendimento humano para que se tenha a garantia da certeza jurídica.

Considerando que o conhecimento somente existe como conhecimento dos sujeitos históricos coletivos, não se pode aceitar que a proficiência do Exame de Ordem se apresente como diretriz dos cursos jurídicos, mas é necessário retomar os projetos pedagógicos para compreender o ensino jurídico em uma dimensão que supere a exigência da compreensão apenas legal do Direito positivado e que resgate a unidade do saber humano emancipatório na universidade. Uma formação jurídica que proporcione a compreensão de que o sistema jurídico, como criação humana, tem a finalidade de concretizar a existência de um mundo melhor. A compreensão de que a esfera jurídica é instrumento e garantia de concretização dos anseios da sociedade, os quais, prescritos na Constituição da República, principalmente como direitos fundamentais a serem prestados pelo Estado, possam ser concretizados pela atuação de sujeitos autônomos. O ensino jurídico pode, além de formar juristas, primar pela formação de cidadãos que tenham cultura jurídica e geral para intervir na sociedade sem que tal atuação ocorra apenas através da advocacia e da atuação judicial.

Pensar a solidariedade social fortalece a dimensão humanística no ensino do Direito em uma universidade, como alternativa de construção da autonomia e do pensamento crítico-reflexivo. Nesta compreensão o ensino jurídico universitário não visa apenas a formação para uma profissão jurídica, sendo compreendido, portanto, como uma grande formação necessária para a vida em sociedade. É por tais razões que não se pode aceitar que avaliações externas apenas utilitaristas sejam aptas a qualificar um curso jurídico como de excelência, já que se limitam a aferir, em regra, conceitos memorizados ou fragmentos de leis. Outros aspectos, além da técnica jurídica, são essenciais para a vida em sociedade, tais como os que dizem respeito à condição humana, aos direitos humanos, à dignidade humana, à constituição da cidadania, os quais são alcançados pela vida autônoma.

O ensino jurídico em uma universidade não pode ser reduzido a uma simples formação para o mercado, como uma técnica jurídica sem uma formação num lastro humanístico. No que se refere à vida em sociedade, os argumentos levantados são suficientes para defender a ideia de que pode contribuir à constituição de seres autônomos que tenham a capacidade de analisar o Direito positivo para avaliá-lo e corrigi-lo para transformar as vidas e a própria sociedade. Em outras palavras, que possam avaliar e corrigir os aspectos legais que estão equivocados e que não correspondam ao anseio de concretização do interesse público.

O conhecimento para a autonomia é a linha lógica a ser perseguida na formação jurídica e possibilita que o sujeito se governe por sua própria razão. Se o curso universitário é a possibilidade 
de conduzir os alunos a buscarem o esclarecimento, por outro lado gera a possibilidade de questionamento da própria ideia de conhecimento, das verdades postas como absolutas, e o enfrentamento para a solução dos problemas humanos e sociais.

Defende-se que a formação profissional comprometida não esteja apartada do mundo da vida, aspecto que implica a necessidade de repensar o humano a partir da compreensão do projeto humano-social e da sociabilidade. Propõe-se uma formação que não abandone os aspectos legais, mas que tenha, na autonomia do sujeito, um instrumento de atuação social para o aprimoramento do contrato social e de ação consciente nesta sociedade imaginada. Sociedade imaginada que está configurada em uma Constituição republicana e que cria um Estado Democrático de Direito, o qual tem em seus princípios fundamentais os preceitos para o bem-estar coletivo.

\title{
LAW AND HUMANITIES: ASPECTS OF HUMAN FORMATION
}

\begin{abstract}
This article is a reflection on human formation in Law courses and notes that legal education, rather than a training in the area of applied social sciences, should have the main concern with human training for life in society. It is a qualitative research with reflection from a theoretical study. It concludes that there is a misunderstanding in the way Law is taught and this teaching is evaluated, which emphasizes the transmission and memorization of legal contents. It emphasizes that it is necessary to rescue the unity of emancipatory human knowledge, that knowledge of the humanistic dimension is what gives meaning to the teaching of law in a university, with construction of autonomy of thought and not as a simple formation for the market.
\end{abstract}

Keywords: Autonomy; Legal education; Education; Social imaginary; Human relations.

\section{Referências}

ADORNO, Theodor. W.; HORKHEIMER, Max. Dialética do Esclarecimento: fragmentos filosóficos. trad. Guido Antonio de Almeida. Rio de Janeiro: Zahar, 1985. 224 p.

AGUIAR, Roberto. Direito, poder e opressão. 2. ed. Rio de Janeiro: Lumen Juris, 2014. 214 p.

ARENDT, Hannah. Entre o passado e o futuro. trad. Mauro W. Barbosa. 7. ed. São Paulo: Perspectiva, 2014. 350 p. 
BENJAMIN, Walter. O anjo da história. Org. e trad. João Barrento. 2. Ed. Belo Horizonte: Autêntica Editora, 2013.

BRASIL. Constituição da República Federativa do Brasil de 1988. Disponível em: $<$ http://www.planalto.gov.br/ccivil_03/Constituicao/ConstituicaoCompilado.htm>. Acesso em: 18 out. 2018.

. INSTITUTO NACIONAL DE ESTUDOS E PESQUISAS EDUCACIONAIS ANÍSIO TEIXEIRA. Censo da Educação Superior: Notas Estatísticas 2017. Disponível em: $<$ http://download.inep.gov.br/educacao_superior/censo_superior/documentos/2018/censo_da_edu cacao_superior_2017-notas_estatisticas2.pdf>. Acesso em: 11 out. 2018a.

. Lei no 8.906, de 4 de julho de 1994. Dispõe sobre o Estatuto da Advocacia e a Ordem dos Advogados do Brasil (OAB). Disponível em: $<$ http://www.planalto.gov.br/ccivil_03/LEIS/L8906.htm>. Acesso em: 25 out. 2018.

. Resolução CNE/CES n ${ }^{\circ}$ 9, de 29 de setembro de 2004. Alterada pela Resolução $\overline{\mathrm{CNE} / \mathrm{CES} \mathrm{n}} \mathrm{n}^{\mathrm{3}}$, de 14 de julho de 2017. Institui as Diretrizes Curriculares Nacionais do Curso de Graduação em Direito e dá outras providências. Disponível em:

$<$ http://portal.mec.gov.br/cne/arquivos/pdf/rces09_04.pdf>. Acesso em: 06 out. 2018.

CASTORIADIS, Cornelius. A instituição imaginária da sociedade. 5. ed. trad. Guy Reynaud. rev. tecn. Luiz Roberto Salinas Fortes. Rio de Janeiro: Paz e Terra, 1982. 420 p.

CONDORCET, Jean-Antoine-Nicolas de Caritat, marquis de. Cinco memórias sobre a instrução pública. trad. e apres. Maria das Graças de Souza. São Paulo: Ed. UNESP, 2008. 264 p.

FENSTERSEIFER, Paulo Evaldo. Epistemologia e prática pedagógica. In: Revista Brasileira de Ciências do Esporte, Campinas, v. 30, n. 3, p. 203-214, maio 2009b.

. Ética e educação: reflexões acerca da docência. In: Educação. Santa Maria, v. 34, n. 3, p. 559-572, set./dez. 2009a.

GRAU, Eros Roberto. O processo legislativo e o processo normativo. Palestra no Instituto dos Advogados Brasileiros (IAB). 1h03min08seg. Disponível em:

$<$ https://www.youtube.com/watch?v=O8VoZMhOMiw>. Acesso em: 09 nov. 2017.

HABERMAS, Jürgen. Teoria do agir comunicativo, 1: racionalidade da ação e racionalização social. 1. ed. trad. Paulo Astor Soethe. rev. Flávio Beno Siebeneichler. São Paulo: WMF Martins Fontes, 2012. $704 \mathrm{p}$.

HEGEL, Georg Wilhelm Friedrich. Introdução à História da Filosofia. Trad. Euclidy Carneiro da Silva. São Paulo: Hemus, 2004. 262 p.

HEISENBERG, Werner. A parte e o todo: encontros e conversas sobre física, religião e filosofia. trad. Vera Ribeiro. rev. Luciana Muniz; Antônio Augusto Passos Videira. rev. tecn. Ildeu de Castro Moreira. Rio de Janeiro: Contraponto, 1996. 288 p.

KANT, Immanuel. Fundamentação da metafísica dos costumes e outros escritos. trad. Leopoldo Holzbach. São Paulo: Martin Claret, 2011. 144 p. 
MALDANER, Otavio Aloisio. A formação inicial e continuada de professores de Química: professor/pesquisador. Ijuí: Unijuí, 2006.

MARQUES, Mario Osorio. Botar a boca no mundo: cidadania, política e ética. Ijuí: Ed. Unijuí, 2003. $84 \mathrm{p}$.

. Conhecimento e educação. Ijuí: Ed. Unijuí, 1988. 190 p.

. Conhecimento e modernidade em reconstrução. Ijuí: Ed. Unijuí, 1993. 128 p.

. Educação nas ciências: Interlocução e Complementaridade. Ijuí: Ed. Unijuí, 2002. 160

p.

. Educação/interlocução, aprendizagem/reconstrução de saberes. Ijuí: Ed. Unijuí, 1996. $144 \mathrm{p}$.

. Pedagogia: a ciência do educador. 3. ed. rev. Ijuí: Ed. Unijuí, 2006. v.5. 188 p.

MLODINOW, Leonard. O andar do bêbado. trad. Diego Alfaro. Rio de Janeiro: Zahar, 2011. $324 \mathrm{p}$.

ORDEM DOS ADVOGADOS DO BRASIL. OAB Recomenda. Disponível em:

$<$ https://www.oab.org.br/servicos/oabrecomenda>. Acesso em: 11 out. 2018.

"Apesar do índice de reprovação, Exame de Ordem deveria ser mais rígido", diz

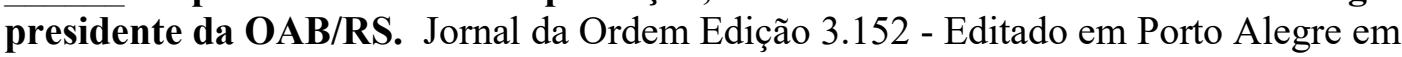
07.02.2019 pelo Departamento de Comunicação Social da OAB/RS. Disponível em: $<$ http://bit.ly/2DZCwqd $>$. Acesso em: 7 fev. 2019.

SANTANA, Flávia Feitosa. A dinâmica da aplicação do termo qualidade na educação superior brasileira. São Paulo: Editora Senac, 2007. 248 p.

TAGLIAVINI, João Virgílio (coord.). Exame de Ordem: uma visão crítica. São Carlos, SP: Edição do Autor, 2010. 220 p.

VYGOTSKY, Lev Semenovich. A formação social da mente: o desenvolvimento dos processos psicológicos superiores. org. Michael Cole [et al.]. trad. José Cipolla Neto, Luís Silveira Menna Barreto, Solange Castro Afeche. 7. ed. São Paulo: Martins Fontes, 2008. 182 p.

Trabalho enviado em 12 de janeiro de 2019

Aceito em 17 de março de 2019 